Studia Anglica Posnaniensia 51/4, 2016

doi: 10.1515/stap-2016-0020

\title{
THE ABSURD AS A REPRESENTATION: TOWARDS A HERMENEUTICS OF THE INEXPLICABLE (THE PROBLEMATIC CASE OF GODOT)
}

\author{
KRYSTYNA RYBIŃSKA* \\ University of Gdańsk
}

\begin{abstract}
This article attempts to re-signify the already extensively discussed conception of the absurd attributed to the aesthetic phenomenon presented by the so-called theatre of the absurd by critically reconsidering its paradigmatic work Waiting for Godot in relation to philosophical hermeneutics (Heidegger, Gadamer, Ricoeur). The fact that Beckett's artistic method invalidates the transparency of the mirror-like relation between reality and art is known, and yet the potential theoretical consequences of such a literary revolution do not seem to have been exhausted - particularly in respect to the category of the absurd. Hence, the presented inquiry aims to view the phenomenon quite against its common conceptualizations derived from existentialist philosophy in order to indicate a possible route of exploring it from a hermeneutic perspective and thereby challenging, to some extent, Simon Critchley's (2004: 165) famous assertion that Beckett's oeuvre seems "uniquely resistant to philosophical interpretation".
\end{abstract}

Keywords: the absurd, hermeneutics, truth, Beckett, representation

\section{Introduction}

Joanna Gavins in the essay The Literary Absurd preceding her most recent book Reading the Absurd (2013) rightly notes that the conception of the absurd appears to be approximately one of the "most nebulous of literary categories".

Corresponding author: PhD Studies Programme, Department of English, University of Gdańsk, ul. Wita Stwosza 51, 80-952 Gdańsk, e-mail: krphilo@gmail.com. 
However, whereas she herself "shifts the discussion of the absurd away from obscure philosophical debate" (Gavins 2012: 67) the idea of this article is to do something different. I would like to add to this discussion of the reconsidered experience of the absurd as not a simple, more or less direct representation of the external existential situation conveyed through artistic measures or through performance. On the contrary I wish to distance this investigation from both pre-artistic experiences and conceptions of absurd and from realm of performance theory in order to analyse the absurd as an experience originating precisely in the complex ontological structure of the work of art. Gavins as well as Bennett appear to follow the existentialist idea of the absurd as inherently bound to the idea of experiencing the absurdity of existence.

Although such a thesis cannot be directly invalidated it needs to be reexamined in the face of the modern philosophical and literary controversy oscillating around the fact that the primal subject-object relation ceases to be transparent, and that to advance this proposition results in the disquieting possibility that "perhaps no relationship exists between or among the artist, his art, and an external reality" (Dearlove 1982: vii) - the thesis that J.E. Dearlove ascribes to Beckett writings. Thus the metaphysical anxiety no longer occurs before the action of a solitary human but rather it permeates the very constricted space before the word as the founding structure of reality we perceive. In this context we may formulate the assertion that the literary experience is in fact transfigured into an existential experience, not the other way around. Hence Butler's argument may appear partly accurate: "If it is true that the meaning of being can only be experienced and not explained it is perhaps the case that literature can come closer to it than philosophy. Samuel Beckett may in fact offer us a purer insight into ultimate reality even than those philosophers most neatly attuned to it" (Butler 1984: 205).

If so, a question arises whether it is possible for literature to deliver an insight into a state of the absence of meaning. Yet, the doubtful premise of such a thesis is the claim that meaning is beyond question assigned to existence for which the work of art is a mere means of expression. In this article I wish to risk the claim that perhaps it is possible to experience both the meaning of being and the lack of it due to the fact that what is, i.e. being, either can or cannot be explained within the no longer transparent structure of representation. The impression of an absence of meaning emanating from the work of art makes possible a negative methodological perspective revealing the metaphysical basis of the absurd conceived as a literary category which, if investigated separately, proves highly refutable. 


\section{Philosophical hermeneutics and the objectivity of meaning in art}

In its first part my article endeavours to present the underlying hermeneutical conditions under which absurdity comes to existence on the theatrical scene. We may provocatively ask: how is it possible that absurdity constitutes meaning in art? The paradoxical nature of this question resides in its reversed resonance given that approaching the absurd as an aesthetic phenomenon makes it possible to either invalidate art's claim for meaning or at least provoke a critical reexamination of this claim. Philosophical hermeneutics provides unique insight into literature since in its pursuit of meaning it addresses not only the extracted existential content of the work of art but it also encompasses its formal aspect and thereby challenges its very ontology.

However, the first question concerns discourse: what does hermeneutics stand for?

... hermeneutics acquires a domain that in principle reaches as far as the expression of meaning as such. Expressions of meaning are first of all linguistic manifestations. .... If we recall the origin of the name hermeneutics, it becomes clear that we are dealing here with a language event, with a translation from one language to another, and therefore with the relation of two languages.

(Gadamer 1977: 98-99)

Let us investigate the first sentences of the passage from Gadamer's essay Aesthetics and Hermeneutics (1964) where he claims that the research ground for hermeneutics is to be a domain of meaningful statements. Given such a thesis appears to imply a merely linguistic meaning the first difficulty appears at this very point - how may the work of theatrical art become an object of hermeneutic study since its nature is not strictly linguistic? Yet, it still definitely constitutes a kind of the work of art which "says something to us and that it thus belongs to the matrix of things we have to understand" (Gadamer 1977: 98). Hence, despite the fact that in the theatre we face a specific phenomenon, it is not excluded from the sphere of "the language of the work of art", since Gadamer recognizes it as:

What we are calling the language of the work of art, for the sake of which the work is preserved and handed on, is the language the work of art itself speaks, whether it is linguistic in nature or not. .... Even the nonlinguistic work of art, therefore, falls within the province of the proper task of hermeneutics. 
According to the author of Truth and Method the language of the work of art constitutes the necessary condition for preserving the work of art itself, which means that it maintains its significance and validity beyond its contemporary scope, understood historically as the time of its temporal origin.

From the conception of hermeneutics outlined by Gadamer we may draw the conclusion that it is in fact the art of making something clear, that is of translating a different language, reality, to one's own. It means that hermeneutics aims at deconstructing a foreign statement in order to re-construct it in the medium of another language. Thus it comprises both a method and a research stance, for which the primal area of analysis is what Gadamer calls a language event, as a relation of two languages and therefore an intersection of two different realities. The author of Truth and Method emphasizes that the necessary condition for the language event to occur, thus allowing us to grasp its diverse spirit, is to understand the meaning of the statement. According to Gadamer the latter consists in the deconstruction of the statement as an action which is prior to translating the statement to one's own language (Gadamer 1977: 98-99). However, to approach the phenomenon of understanding as such it is crucial that we elucidate the very object of hermeneutical deconstruction, as the above conclusions indicate it to be a statement in the medium of language.

In light of the above account, what is added to the reality of the language event is the element of logos outlined as if beyond its horizon. The notion of logos necessarily bears a reference to language, which was previously conceived as a medium; here, however, it also discloses its essential and intrinsic metaphysical characteristic. Therefore, provided that its primal reality is speech, language appears to be a process comprised of two layers: the conscious application of language as a tool or a medium; and the underlying unconsciousness of the fact of being immersed in language as logos. Correspondingly Gadamer asserts in his essay Man and Language (1966): "for it is part of the nature of language that it has a completely unfathomable unconsciousness of itself" (Gadamer 1977: 62). Therefore it reaches even deeper than the course of the direct usage of language, since in the direct application of language its unconsciousness can be overcome in the process of translation. However, Gadamer reveals the fundamental truth that we "are always already biased in our thinking and knowing by our linguistic interpretation of the world" (Gadamer 1977: 64). Whereas the negative, reverse aspect of this sentence indicates that language is in fact the most primal and intrinsic axiom that is presupposed in the process of cognition, the positive side of Gadamer's claim implies that reality itself is linguistic by nature. Thus we may draw a conclusion that the situation of humans in the world is by nature dialogical. So Gadamer claims: 


\begin{abstract}
A second essential feature of the being of language seems to me to be its I-lessness. Whoever speaks the language that no one else understands does not speak. To speak means to speak to someone.
\end{abstract}

(Gadamer 1977: 65)

Hence what is fundamental for a human being's dialogical mode of existence in the world is the essential moment of transcending oneself towards what is ultimately different - otherness. This basic characteristic of a human being allows it to sustain the inner dynamic of existence itself.

However, at this point an indispensable question arises: what primal quality does the dialogical nature of human existence imply? Again Gadamer suggests a trace: "language is the real mark of our finitude. It is always out beyond us" (Gadamer 1977: 64). What does it mean that language is "always out beyond us?" I believe it implies that language as meaningful whole, logos constitutes a totality which transcends the language event while the latter, according to Gadamer, essentially reveals the previously mentioned intersection of two realities. Therefore language as logos necessarily surpasses our contemporary existence. This conclusion is derived from the third aspect of language - its universality: "Language is all-encompassing. There is nothing that is fundamentally excluded from being said, to the extent that our act of meaning intends it" (Gadamer 1977: 67). This passage indicates that the real nature of logos is transcending universality and being a process. In the face of this assertion we appear to become merely the virtual rulers of conversation, that is, language usage. Therefore every, no matter how radical, intervention in language as a tool is condemned to only partial success due to the linguistic facet of reality.

Consequently, in accordance with the notion of logos transcending the dialogical situation of two diverse intersecting realities, Gadamer may legitimately claim that the "universality of the hermeneutical perspective is allencompassing" (Gadamer 1977: 103) and thereby provide the necessary condition for hermeneutics being possible as not just a method and epistemological perspective but as an ontology. Thus conceived hermeneutics presupposes an assumption of the world's linguistic nature. Yet, it appears to be a paradox that according to Gadamer such a thesis does not convey a metaphysical truth about the world. On the contrary, it rather reveals a fundamental truth about man which resides in the fact that there "is nothing that cannot mean something to it" (Gadamer 1977: 103). Whereas meaning is what Ricoeur places in opposition to the event,

[t]he suppressing and the surpassing of the event in the meaning is a characteristic of discourse itself. It attends to the intentionality of language, the relation of noesis and noema in it. In language is meinen, an 
intending, it is so precisely due to this Aufhebung through which the event is cancelled as something merely transient and retained as the same meaning.

(Ricoeur 1976: 12)

Language according to Ricoeur is an event that "is realized temporally and in a present moment" (Ricoeur 1976: 11); it transcends itself in meaning. This is its truth as system. This process constitutes the difference between what is said and the very act of saying. Thus, the ambiguity of language as simultaneously a logos and a process, expressed via the opposition of the event and meaning, indicates that dialectics is its ultimate nature.

3. Waiting for Godot - literary chaos as a critical insight into the descriptive configuration of theatrical art

In order to investigate the phenomenon of the absurd performed by the theatre of the absurd it appears only adequate to begin with the study of the very experience of watching a play of the kind. To that end let us direct the analysis backwards in time to the very premiere of the play Waiting for Godot in the Babylone Theatre in 1953. It appears that considering the theatrical criteria of the time nothing really happened on the stage. We face the same representation nowadays - the image of a deserted road as though dully diverted by a desolate dead tree and two men. From the inconsistent conversation of Vladimir and Estragon one may deduce that they are waiting for someone vaguely named Godot who is supposed to hire them. The audience is forced to watch these two characters dimly suspended in almost oppressive inertness expressed by Estragon's significant statement "Nothing to be done" (Waiting for Godot, 12) and almost mirroring "show all the same" (Waiting for Godot, 86). There occurs the attempt to break the enchantment by means of suicide yet the plan itself is not carried out and with all its humorous circumstances seems devoid of a real potency whatsoever. In the meantime a grotesque pair approaches, Pozzo and Lucky. This fact might even be distracting in its weirdness were it not for the overwhelming atmosphere of impassivity. Simultaneously with the end of the first act a boy arrives - a messenger from Godot ensuring that Godot is unable to come today but will surely come tomorrow. The second act constitutes a paraphrase of the previous one, an illustration of another day of waiting for Godot. Again Lucky and Pozzo enter; their roles are switched but the nature of their relation of abuse remains unaffected. Again the boy appears acting as though arriving for the first time. He even fails to remember Vladimir and Estragon from their previous encounter. 
In such a manner the action of the play is presented - filled with dialogues and proceedings which may appear devoid of meaning. Further, it seems to manifest its failure to convey either culmination point or an outcome. We may therefore ask: in what way does the work of theatrical art acquire the potency of meaning? It obtains it by the inner, formal totality which resides in both the indispensible necessity and the universality that are the essential characteristics of the work of art. According to Adorno (2002: 104), the meaning of Beckett's works as well as of modern art as such is to emphasize and reveal the formal unity of the work of art as its inherent mimetic force and to provide a critical insight into it.

Yet, quite despite a consistent formal facet Hayman in Theatre and AntiTheatre: New Movements Since Beckett incorporates of Beckett's plays in the anti-artistic movement:

To use the term 'anti-theatre' is to emphasize the negative, destructive, revolutionary, reductionist and abstractionist tendencies in the new theatrical art. The anti-play is less mimetic than satirical, not so much a story about life in a particular time as an object in its own right. Nonreferential, implicitly denying the feasibility of referential art.

(Hayman 1979: 6)

In the passage above Hayman describes the tendencies of anti-theatre which allow us to define it as an element of an anti-art movement as such. These affinities aspire to constitute the play as exclusively detached from everyday life - non-referential, twisted in its construction and embedded in a context extraneous to traditional drama. However, apart from this established negative, critical tendency of Beckett's theatre, his shift of emphasis in stage proceedings may also demarcate the artistic progress, indicated by Cohn in his Just Play: Beckett's Theatre. The process is directed towards revealing the 'theaterreality' by extracting the very tensions from within the plays, which are, Cohn argues, "excruciatingly concrete" (Cohn 1980: 12). At this point we may arrive at a conclusion that the formal tensions that constitute the concrete 'theaterreality' in Beckett's drama form an aesthetic content which is in turn self-reflectively represented in the artwork. The drawn conclusions mark Beckett's severance with the representative idea of art conceived as a medium for existential experiences extracted from "real life".

Simultaneously, the anti-art movement - despite the apparent abandonment of former artistic categories - unveils the essence of art in terms of modern philosophical hermeneutics. As Ricoeur puts it: “... the text must be unfolded, no longer toward its author, but toward its immanent sense and toward the world it opens up and discloses" (Ricoeur 1991: 63). According to the author, the adequate mode of existence of the work of art fundamentally consists in its 
autonomy, as opposed to its being diffused in the context of origin. In this asset resides the artwork's immanency of meaning, which is a condition of its enduring validity.

In fact, an absolute contemporaneousness exists between the work and its present beholder that persists unhampered despite every intensification of the historical consciousness. The reality of the work of art and its expressive power cannot be restricted to its original historical horizon, in which the beholder was actually the contemporary of the creator. It seems instead to belong to the experience of art that the work of art always has its own present.

(Gadamer 1977: 95)

In the above passage Gadamer indicates that the endurance of the work of art implies its absolute contemporaneousness within every aesthetic experience, since the artwork as well as the viewer is always contemporary towards one another. Therefore, in spite of its non-referentiality the work of art seems to designate a basically existential truth by virtue of its absolute contemporaneousness in relation to the viewer.

However, the existential experience constituted upon the contemporaneousness of the work of art toward the viewer does not imply a rescindment of the previously established severance of Beckett's drama from the idea of conveying existential experience as a content through art as a medium. On the contrary, it only indicates that the experience has been dislocated from its assumed literary territory and simultaneously countermands the existentialist's presupposition that it originates outside of the work of art, via which it is only conveyed. What Beckett appears to emphasize here is the fact that existential experience is located strictly within the realm of the formal aspect of the work of art. Hence to force the artwork's representative powers to point critically inward towards its structure would bring forth a new category of the absurd.

\section{Transgressing the chaos. Quid est veritas?}

The thesis established by Esslin, and thoroughly criticized by Bennett, that the purpose of the theatre of the absurd is to show the absurd would suggest that the metaphysical experience is inherently connected to experiencing the absurdity of life. As far as this proposition may appear stale in Beckett scholarship it does carry a potentially important intuition, since according to the author of The Theatre of the Absurd both the theatre of the absurd and the philosophy of the absurd strive to convey and express the absurdity of existence. Yet what differentiates them is the means of expression. The theatre of the absurd in opposition to the philosophy of the absurd is not entangled in the discourse 
concerning the logical rules of language but is in fact an uncontaminated expression of modern human experience - the absence (Esslin 1974: 6) of meaning. Although Esslin fails to critically reconsider the existential notion of the absurd he does emphasize an important difference between the reducible premises inherent in Sartre's philosophy and irreducible attributes of Beckett's writings, when he remarks that in Beckett language is subjected to absurdity in order to reveal the fundamental relation of form and substance and the parallel relation of idea and chaos. This point Theodor Adorno discusses in his essay on Endgame:

But whereas in Sartre the form - that of the piece a these - is somewhat traditional, by no means daring, and aimed at effect, in Beckett the form overtakes what is expressed and changes it. The impulses are raised to the level of the most advanced artistic techniques, those of Joyce and Kafka. For Beckett absurdity is no longer an "existential situation" diluted to an idea and then illustrated. In him literary method surrenders to absurdity without preconceived intentions. Absurdity is relieved of the doctrinal universality which in existentialism, the creed of the irreducibility of individual existence, linked it to the Western pathos of the universal and lasting.

(Adorno 1992: 241)

Here he claims that, unlike in Sartre where dramaturgy is inherently bound to the idea of the existential absurd, the dramaturgy of Beckett abandons this last artistic illusion and, utterly disposing form of its servile function towards idea, it is free to speak the truth of what is individual and released from the limits of any totality. The very end of the play constitutes such an example of selfextinguishing culmination point following an unaccomplished suicide and never fulfilled decision to leave the place of waiting:

VLADIMIR: Well, shall we go?

ESTRAGON: Yes, let's go.

[They do not move.]

(Waiting for Godot, 87)

At the point when the seemingly appropriate culmination point would be to either abandon the place or commit suicide the action terminates at failure and everything seems ready to repeat itself. Repetition, or its promise, takes place of the culmination point surrendering to the fact that there is no release - given such is the very dictum of the content. As the form is entirely subjected to the latter thus the restored speech is indeed chaos, and the form itself fails to refer beyond it. Instead it points insistently inwards unveiling its own artistic structures as well as the fathomless void unfolding behind them - the possibility of reductio ad absurdum. Thus the intellectual facet of interpretation as a 
necessary element of aesthetic experience in both Adorno and philosophical hermeneutics in face of Beckett's plays cancels itself under its self-coercion. Adorno's conclusion justifies the apparent anarchy in the construction of the play resulting in its incomprehensibility. Furthermore, it corresponds with Beckett's words emphasizing the relationship between form and chaos in the famous interview with Tom Driver:

It only means that there will be new form, and that this form will be of such a type that it admits the chaos and does not try to say that the chaos is really something else.

(Beckett in Oppo 2008: 70)

Reflecting on Beckett's words we may draw the conclusion that chaos is a common state of being, present and yet just recently admitted, which means that until now it has remained concealed. Nevertheless, the question reoccurs whether the chaos does in fact denote the content understood as the existential condition. J.E. Dearlove (1982: vii), already mentioned in this article, would presumably argue otherwise in his book Accommodating the Chaos: Samuel Beckett Nonrelational Art, which "examines Beckett's unremitting efforts to find a literary shape for the proposition that perhaps no relationship exists between or among the artist, his art, and an external reality". Although such efforts are far better illustrated in Beckett's later works we may already see traces of them in Waiting for Godot, for instance in examples of occurring selfawareness of Vladimir:

At me too someone is looking, of me too someone is saying, he is sleeping, he knows nothing. Let him sleep on. [Pause.] I can't go on! [Pause.] What have I said?

(Waiting for Godot, 83)

In this short passage we come across emerging awareness of the play, refusal to participate and final surrendering to it. One cannot escape the impression that such a practice on the behalf of the author resembles throwing stones into the water, disturbing its mirror like surface. Although Dearlove's apparently radical thesis may provoke a temptation to perceive Beckett's oeuvre from the standpoint of its inherent potency for disintegration and collapse, yet the reverse side of his statement provides a new possibility to investigate the notion of chaos. To follow that trace we may ask what is the source of chaos, the dialectics of form and content?

I believe that in order to answer this question it is crucial to recall the hermeneutic's stance concerning the nature of reality as linguistic structure discussed in the first part of this article. Respectively, in What is Truth Gadamer states: 
But hiddenness belongs just as much to human action and speech. Human speech does not contain everything that is true; it knows also appearance, deceit, and pretense. There is an original connection between true being and true speech.

(Gadamer 1994: 36)

Concealment is an essential aspect of human speech; it is primal to language. At this point it seems important to mention that among many insights made into connections between works of Beckett and the philosophers the important step seems to be taken by P.J. Murphy in his essay Beckett and the Philosophers (1994). By bringing Beckett in proximity with Kant Murphy emphasizes that Beckett's aim is not to drain meaning from language but to reflect on the nature of its relation to the world. If we advance this thesis further by taking into account the roots of language in speech and its concealing nature, this very relation proves inherently disrupted. The characteristic of speech itself is that of truth and lie, since the possibility of ambiguity is always inherent in the nature of speech. Yet, by the fact of this inherence it implies simultaneously the truth. How is this conveyed in Beckett's drama? Hayman (1979: 5) notes that anarchy and the atrophy of stage measures in Beckett's drama is in fact a deliberate reduction of both image and motion which aims at revealing dialogue as the only prevailing reality. Taking into account that the viewer is not disposed towards assuming that dramatic form and reality possess a mirror-like relation, it appears that the ultimate sense of the play is the conviction that there is no other reality than the dialogue, or rather thinking as such. However, thinking according to Gadamer is rooted in language contaminated with the possibility of ambiguity. As Carla Locatelli notes in Unwording the World this process is equally detectable in Beckett's prose when she reflects on self-referential aspect of language in The Lost Ones: "Beckett ... brings the impossibility of pure description before our eyes, showing how blurred the distinction between 'said' and 'saying' may be" (Locatelli 1990: 246). Here Locatelli's remark signifies the crystallization of an independent object in Beckett's works - the selfconscious narrative structure of meaning. Although the phenomenon is more visible in Beckett's later works, yet the very primal shift of the meaning from the outside reality to the ecliptic nature of words and monologues spoken by the characters is already observable in Waiting for Godot:

VLADIMIR: I've seen you before, haven't I?

BOY: I don't know sir.

VLADIMIR: You don't know me?

BOY: No, sir.

VLADIMIR: It wasn't you came yesterday?

BOY: No, sir. 
VLADIMIR: This is your first time?

BOY: Yes, sir.

[Silence.]

VLADMIR: Words, words. [Pause.]

(Waiting for Godot, 44)

Vladimir becomes aware that neither what he saw and heard nor what really happened or was said is true, but that what is happening and his own fate depends on words alone. What is more it seems that meaning constituted by words spoken before is cancelled by the words spoken now and so the course of action is determined by the disrupted constant narrative.

Again, from the hermeneutic perspective Beckett appears to present Ricoeur's conception of meaning as content in the work of art, thereby provoking a critical interpretation of it. It is from this dialectical feature of language that Heidegger's concept of truth as aletheia is derived ${ }^{1}$ and thus we approach the origins of modern philosophical hermeneutics. The essence of truth discerned in this way emerges from the reversed question about the truth of essence. Why the reversion?

The question of the essence of truth arises from the question of the truth of essence. In the former question essence is understood initially in the sense of whatness (quidditas) or material content (realitas), whereas truth is understood as a characteristic of knowledge. In the question of the truth of essence, essence is understood verbally; in this word, remaining still within metaphysical presentation, Being is thought as the difference that holds sway between Being and beings.

(Heidegger 2008: 256)

Thus formulated the question of the essence of truth positions the notion of essence in a place of a noun, i.e. an object, in order to force the question of "what" upon it. The question of truth is reduced to the trace of cognition conceived as the compatibility of thought and object. Whereas, as Heidegger explains, the question of the essence of truth delivers a new perspective in understanding the phenomenon through its happening. The conceived notion of being-ness aims at emphasizing the very moment of becoming of essence in its temporality. The essence never really is but infinitely becomes. What is truth in the light of this?

\footnotetext{
Simultaneously, we bring Beckett into proximity with Heidegger's philosophy. It is important to note that such attempts have already been made by a many recognized critics such as the already mentioned here Lance St John Butler in his book Samuel Beckett and the Meaning of Being and Simon Critchley's Very Little... Almost Nothing. However, the presupposition that seems to overshadow these interpretations is the lack of substantial distinction between Heidegger's philosophy and the Parisian existentialism.
} 
Truth signifies sheltering that lightens [lichtendes Bergen] as the basic characteristic of Being. The question of the essence of truth finds its answer in the proposition the essence of truth is the truth of essence. After our explanation it can easily be seen that the proposition does not merely reverse the word order so as to conjure the spectre of paradox. The subject of the proposition - if this unfortunate grammatical category may still be used at all - is the truth of essence. Sheltering that lightens is - i.e., lets essentially unfold - accordance between knowledge and beings.

(Heidegger 2008: 253)

The truth is a fundamental trait of being making a clearance in its concealment. Thereby it might be concluded here that the nature of being is concealment, while truth provides a clearing which happens by the very virtue of being: the ontological difference between existence and being. However, as the previously cited passage implies, being itself may provide a clearance which however is not equal with unveiling. Thus what may be perceived through the clearance is the concealment itself. Concealment, according to Heidegger, allows errancy, and wandering in errancy:

The disclosure of beings as such is simultaneously and intrinsically the concealing of being as a whole. In the simultaneity of disclosure and concealing errancy holds sway. Errancy and the concealing of what is concealed belong to the primordial essence of truth.

(Heidegger 2008: 254)

What is errancy?

Man's flight from the mystery toward what is readily available, onward from one current thing to the next, passing the mystery by - this is erring.

(Heidegger 2008: 253)

In the light of Heidegger's words wandering in errancy stands for running around which reminds one of the modern hustle and bustle, of being immersed in what is current. What can be current? Opinion or truth. Here current stands for something that is not mine but accepted and applied to my own mode of being. What is more, running around happens in spite of the mystery and away from it. Thus the concealment of being is a mystery of individual being [Dasein].

As insistent, man is turned toward the most readily available beings. But he insists only by being already ek-sistent, since, after all, he takes beings as his standard. However, in taking its standard, humanity is turned away from the mystery. The insistent turning toward what is readily available and the ek-sistent turning away from the mystery belong together.

(Heidegger 2008: 253) 
By applying the term insist to Dasein Heidegger implies being immersed in what is current, as we try to lean on it. To lean denotes not to stand on your own. The difference between ek-sistence and insistence is a characteristic of the human being both in his authentic being and is his tendency to fall [Verfallen] into Das Man - the surrounding world of concern as immersion in what is current and designated as wandering in errancy as such. Thinking which is essential to the authentic mode of being disappears in another mode of being which Heidegger calls Das Man, as the appropriate thinking is in fact thinking of being as either concealed or not. Being in concealment denotes mystery and is conceived of as an intrinsic and primal inclination of Dasein. Concealment which belongs to the essence of Being delivers a possibility of falling into the inauthentic mode of being of Dasein: wandering in errancy in the sphere of truth. That concealment indicates reality as a realm of the unknown seems to be a motto of Beckett's works, and to investigate it provides an interesting perspective for understanding his plays.

In Waiting for Godot we may observe that Vladimir and Estragon are indeed wandering in errancy immersed in habitual proceedings which appear to be as if overemphasized throughout the play. However, what is important: they do seem to be aware of this fact.

VLADIMIR: All I know is that hours are long, under these conditions, and constrain us to beguile them with proceedings which - how shall I say - which may at first sight seem reasonable, until they become a habit. You may say it is to prevent our reason from foundering. No doubt. But has it not long been straying in the night without end of the abyssal depths? That's what I sometimes wonder. You follow my reasoning?

(Waiting for Godot, 72)

Nevertheless Vladimir's words like his actions seem to extinguish and terminate at nothingness which is marked by Estragon's ironic response: "We all are born mad. Some remain so" (Waiting for Godot, 72). This indicates that words may also become dead - habitual. The scene bears intrinsic connection to yet another factor characterizing the atmosphere of the play:

VLADIMIR: We wait. We are bored. [He throws up his hand.] No, don't protest. we are bored to death, there is no denying it. Good. A diversion comes along and what do we do? We let it go to waste. Come. Let's get to work! [He advances towards the heap, stops in his stride.] In an instant all will vanish and we'll be alone once more, in the midst of nothingness!

(Waiting for Godot, 73) 
Boredom in Waiting for Godot is discussed by James Philips in his essay Beckett's Boredom. Philips indicates that pensiveness of both action and characters' proceedings corresponds with Heidegger's complex idea of boredom as atonement. According to the author of the essay the distinctive nature of boredom as an atonement, given the way it is applied in Beckett's works resides in the fact that boredom "privatises, not by withdrawing the subject from the world but by individuating the exposure of an existence to its world" (Philips 2009: 115). Hence, in a way, the world shrinks to the size of one's perspective which in turn is a mere emanation of subject's preconditions - language.

However, despite the oppressive, impassive atmosphere of the play what is even more oppressing is the reoccurring anxiety connected to passing time and inevitably approaching oblivion: "They give birth astride of grave, the light gleams an instant, then it's night once more" (Waiting for Godot, 82). Pozzo's significant statement is soon repeated and expanded by Vladimir:

Astride of grave and difficult birth. Down in the hole, lingeringly, the grave-digger puts on the forceps. We have time to grow old. The air is full of our cries. [He listens]. But habit is great deadener. [He looks again at Estragon.] At me too someone is looking, of me too someone is saying, he is sleeping, he knows nothing, let him sleep on.

(Waiting for Godot, 83)

The repetition as a recognizable feature of Beckett's dramatic works ${ }^{2}$ signifies the inner counter-dynamics of extinguishing underlying the play. Repetition works like habit and maintains wandering in errancy. However, Vladimir's fear of being forgotten marks his desperate need of a witness, which reminds one of Gadamer idea of dialogical consciousness. This point is also discussed by Shimon Levy in Samuel Beckett. Self-referential Drama: The Three I's where the author emphasizes that Gadamer's principle of dialogical self-consciousness "holds true, in a uniquely theatrical way, in Beckett's plays" (Levy 1990: 4). However, the need for a witness is grounded in an essential question expressed by Vladimir:

Was I sleeping while the others suffered? Am I sleeping now? Tomorrow, when I wake, or think I do, what shall I say of today? That with Estragon my friend, at this place, until the fall of night, I waited for Godot? That Pozzo past with his carrier, and that he spoke to us? Probably. But in all that what truth will there be?

(Waiting for Godot, 83)

2 Repetition as a mark of Beckett's work is extensively discussed in reference to Critical Theory by Steven Connor (1988). Albeit among insightful investigations of Beckett works from the perspective of Derrida and Deleuze and Lacan Connor makes reference to Heidegger only once, where he speaks of Beckett's narrators in proximity with Heidegger's conception of being-thrown (Connor 1988: 44). 
From Vladimir's words we may draw the conclusion that whereas truth is opposed to sleep it does coincide with being aware of the suffering of others. The idea seems to be elucidated by Beckett in an interview with Driver:

I life and death did not both present themselves to us, there would be no inscrutability. If there were only darkness, all would be clear. It is because there is not only darkness but also light that our situation becomes inexplicable .... The question would also be removed if we believed in the contrary - total salvation. But where we have both light and dark we have also the inexplicable.

(Beckett in Olney 1998: 15)

The area of the unexplored demarcates the sphere of the real, whereas the inexplicable distinguishes a deeper reality of an ethical paradox in which the ambiguity of injustice appears. Thus Beckett continues:

Take Augustine's doctrine of grace given and grace withheld: have you pondered the dramatic qualities of this theology? Two thieves are crucified with Christ, one saved and the other damned. How can we make sense of this division?

(Beckett in Olney 1998: 15)

The similar motif of the two villains who were crucified with Jesus is put into Vladimir's mouth by Beckett at the very beginning of the play. Injustice is a phenomenon of theological nature. However, when it is also conceived of as an injustice of fate, it constitutes a hermeneutic phenomenon. That something appears as unjust simply means that it is incomprehensible and in spite of being inexplicable it still happens and amounts to a course of individual history, which perceived as a whole carries the inherent question of meaning. Hence the experience of paradox, or rather the absence of meaning. Thus truth becomes relative:

What is truer than anything else? To swim is true, and to sink is true. One is not truer than the other. One cannot speak any more of being; one must speak only of the mess.

(Beckett in Graver \& Federman 1979: 242)

The process of the concealment of Being seeking the truth terminates at the question of Pontius Pilat: quid est veritas? behind which one perceives the echo of mocking laughter mingled with despair. 
But I was not made for the great light that devours, a dim lamp was all I had been given, and patience without end, to shine on in the empty shadows.

(Beckett 2009: 103)

Yet, the deliberate staging of the "wandering in errancy" by Beckett infused with the underlying anxiety ingrained in Vladimir's attitude exposes something more of the nature of truth, apart from the parallel to Heidegger notion of aletheia drawn above. It is the possible and disturbing abstract character of the conception of truth, expressed in the notion of mess. Even more disquieting here is Beckett's demand to speak of it, as though it was the only certain thing. The established sphere of the inexplicable corresponds directly with Beckett's sphere of the inexpressible emphasized in his famous dialogue with Georges Duthiut:

... there is nothing to express, nothing with which to express, nothing from which to express, together with the obligation to express.

(Beckett 1984: 139)

Beckett's thesis does not imply that nothing can be asserted about reality. On the contrary, it appears to endorse the fact that what exists is merely an assertion of reality. The constituted meaning unfolds itself in the endless dialogue. As Gadamer puts it, the "capacity for saying keeps pace untiringly with the universality of reason", concluding "every dialogue also has an inner infinity and no end" (Gadamer 1977: 67). Still, what is even more disquieting is the lurking possibility that this ceaseless narrative may be equally either meaningful or meaningless, as meaningfulness is in fact only an assumption. Hence in the first place, Beckett seems to lay emphasis on the illusory nature of the hypothesis that there is a connection between reality and art, and consequently between subject and object. Whereas the only real, persistent, and absurd demand is the "obligation to express", to "carry on", inherent in artistic activity.

However, we may ask the question: what is there to express after all? Perhaps an ambiguous fear of oblivion on the one hand, and anxiety that there is nothing behind all things, on the other. Therefore Beckett ads a reversed perspective to the hermeneutical stance. While hermeneutics strives to embed reality in a diffuse idea of meaning and impose interpretative powers upon it, Beckett seems to be consistently pointing out throughout his works that although the idea of meaning is indispensable, it does not necessarily present any evidence of what it presupposes - a pre-existing reality. Thus what is particularly disturbing in Molloy's speech is neither the dimness of his lamp nor even the silent, ridiculous demand to shine but the emptiness of the shadows it casts its feeble light upon. The elicit reference to Plato's cave might even be 
comforting were it not for the fact that the source of light is devoid of the magnitude attributed to universal reason. Instead it symbolizes only an abysmally solitary and un-substantial subject.

\section{Conclusion}

The indicated negative conception of the absurd thus surfacing in Beckett's artistic proceedings contradicts the preconceived idea of the transparency of aesthetic representation which mistakes artistic content for the external element extracted from reality and sublimated into the work of art. Thus it diffuses the literary category of the absurd in the vague idea of the so-called absurdity of life. By contrast, the conception of the absurd in Beckett's drama appears to signify a critical insight into the category of meaning unveiling perceptive reality as a very fragile structure founded upon (or locked within) a merely selfreferential concept. ${ }^{3}$ Thus the absurd denotes the necessary and incontrovertible premise of a ceaseless underlying narrative once exposed as the Cartesian ego cogito, although it appears that Beckett would rather refer to the primal negative dubito ergo sum with the emphasis on dubito. ${ }^{4}$ Within such a representation of the absurd meaning is not cancelled, but its transcendence, the characteristic accentuated in Ricoeur's opposition of language event and meaning, is exposed as the negative axiom of an undeniable and yet transient narrative.

3 Among many other ironical references to philosophy Beckett points out the solipsist selfreferenciality of Cartesian idea of subjectivity in Molloy through the image of man in the middle of the forest, who does his "best to go in a circle, hoping in this way to go in a straight line" Beckett (2009: 78).

4 It is known that before Descartes formulated his famous conclusion its reverse negative reflection dubito ergo sum was previously claimed by St. Augustine. Please note that the connection of Beckett oeuvre to negative theology is also indicated by Pascale Casanova in his Samuel Beckett: Anatomy of Literary Revolution (2006) as a part of Irish artistic heritage, as well as by Shira Wolosky in her book Language Mysticism: The Negative Way of Language in Eliot, Beckett, and Celan (1995). In the latter the author also points out that: "Beckett suggests how language establishes the very terms for the ideals that require the transcendence of language" (Wolosky 1995: 4) thereby implying Beckett's subversive attitude towards language. 


\section{REFERENCES}

\section{PRIMARY SOURCES}

Beckett Samuel. 1984. Three conversations with Georges Duthuit. In Ruby Cohn (ed.), Disjecta: Miscellaneous writings and a dramatic fragment, 138-146. New York: Grove Press.

Beckett, Samuel. 2006. Waiting for Godot. London: Faber and Faber.

Beckett, Samuel. 2009. Three novels: Molloy, Malone dies, The Unnamable. New York: Grove/Atlantic.

Gadamer, Hans-Georg. 1977. "Man and language" and "Aesthetics and hermeneutics". In Philosophical hermeneutics, Trans. David E. Linge, 59-69, 95-104. California: University of California Press.

Gadamer, Hans-Georg. 1994. What is truth? In Brice R. Wachterhauser (ed.), Hermeneutics and truth, Trans. Brice R. Wachterhauser, 33-46. Evanston, IL: Northwestern University Press.

Heidegger, Martin. 2008. On the essence of truth. In José Medina \& David Wood (eds.), Truth: Engagements across philosophical traditions, 243-257. Oxford: Blackwell Publishing.

Ricoeur, Paul. 1976. Interpretation theory: Discourse and the surplus of meaning. Fort Worth: Texas Christian University Press.

Ricoeur, Paul. 1991. From text to action. Essays in hermeneutics II. Trans. Kathleen Blamey \& John B. Thompson. Evanston, IL: Northwestern University Press.

\section{SECONDARY SOURCES}

Adorno, Theodor. 1992. Understanding Endgame. In Rolf Tiedemann (ed.), Notes to literature. Volume 1, Trans. Shierry Weber Nicholsen, 216-241. New York: Columbia University Press.

Adorno, Theodor. 2002. Aesthetic theory, Trans. Robert Hullot-Kentor. New York: Continuum.

Bennett, Michael Y. 2011. Reassessing the theatre of the absurd: Camus, Beckett, Ionesco, Genet, and Pinter. New York: Palgrave Macmillan.

Butler, Lance St. John. 1984. Samuel Beckett and the meaning of Being: A study in ontological parable. Basingstoke: Palgrave Macmillan.

Casanova, Pascale. 2006. Samuel Beckett: Anatomy of literary revolution. London: Verso.

Cohn, Ruby. 1980. Just play: Beckett's theater. Princeton: Princeton University Press.

Connor, Steven. 1988. Samuel Beckett: Repetition, theory and text. Oxford: Basil Blackwell.

Critchley, Simon. 2004. Very little... Almost nothing: Death, philosophy, literature. London \& New York: Routledge.

Dearlove, J.E. 1982. Accommodating the chaos: Samuel Beckett nonrelational art. Durham: Duke University Press.

Esslin, Martin. 1974. Theatre of the absurd. London: Methuen.

Federman, Raymond \& Lawrence Graver. 2013. Samuel Beckett. London: Routledge.

Gavins, Joanna. 2012. The literary absurd. In Joe Bray, Alison Gibbons \& Brian McHale (eds.), The Routledge companion to experimental literature, 62-74. London: Routledge.

Gavins, Joanna. 2013. Reading the absurd. Edinburgh: Edinburgh University Press.

Graver, Lawrence \& Raymond Federman (eds.). 1979. Samuel Beckett. The critical heritage. London: Routledge \& Kegan Paul.

Hayman, Ronald. 1979. Theatre and anti-theatre: New movements since Beckett. London: Secker \& Warburg. 
Hunt, Hugh. 1962. The live theatre: An introduction to the history and practice of the stage. London: Oxford University Press.

Ihde, Don. 1971. Hermeneutic phenomenology: The philosopher of Paul Ricoeur. Evanston: Northwestern University Press.

Levy, Shimon. 1990. Samuel Beckett. Self-referential drama: The three I's. London: Macmillan.

Locatelli, Carla. 1990. Unwording the world: Samuel Beckett's prose works after the Nobel Prize. Philadelphia: University of Pennsylvania Press.

Murphy, P.J. 1994. Beckett and the philosophers. In John Philling (ed.), The Cambridge companion to Beckett, 222-240. Cambridge: Cambridge University Press.

Olney, James. 1998. Memory and narrative: The weave of life-writing. Chicago: University of Chicago Press.

Oppo, Andrea. 2008. Philosophical aesthetics and Samuel Beckett. Bern: Peter Lang.

Philips, James. 2009. Beckett's boredom. In Barbara Dalle Pezze \& Carlo Salzani (eds.), Essays on boredom and modernity. (Critical Studies Series.) Amsterdam \& New York: Rodopi.

Wolosky, Shira. 1995. Language mysticism: The negative way of language in Eliot, Beckett, and Celan. California: Stanford University Press. 